\title{
Media-based Social Solitude: An Exploratory Study of Students in a Coffeehouse
}

\author{
By Susan Barnett* \\ Irene Ingeborg van Driel ${ }^{\dagger}$
}

The purpose of this exploratory phenomenological study was to understand how college students engage in media-based social solitude in an informal social space of a coffeehouse. Media-based social solitude is the act of being alone together, physically or virtually, with others through the use of media devices. Multiple data collection methods such as field observation and interviews were used to identify two main themes of engagement in media-based social solitude. The interpretation of data from observations of fifteen students and interviews with ten students provided emergent themes that included the need for reinforcement of others to focus on and accept media in a social space. Understanding media-based social solitude in the context of leisure is important, as media inserts itself into all aspects of a life, and may alter the leisure dynamics within a public space. Additional research in the area of media-based social solitude is necessary to gain a deeper understanding of the phenomenon within leisure and media studies.

Keywords: leisure, Millennials, media-based social solitude, media use, phenomenology

\section{Introduction}

While sitting in a local coffeehouse for hours on end, one begins to notice the intricacies of the space, the people who fit within it, and the way media helps shape or disassemble social interaction. Around the globe, local gathering places, such as a coffeehouse, café, club, and other public places, offer a unique opportunity for people to gather and interact through a commonality - a shared experience in some way. This commonality, such as the location in a neighborhood, provides socialization rooted in centuries of gathering together to share information or gossip in one's free time away from work or home obligations.

This sharing of information is what would have been seen in Europe during the $17^{\text {th }}-19^{\text {th }}$ centuries, when coffeehouses, often referred to as "Penny Universities", were the gathering place of men who could pay the penny entrance fee to participate in the cultural exchange of information by literate men to engage all men in community issues (Oldenburg, 1999, p. 185). The feeling of being involved in sharing information or gossiping can lead to a sense of community. For women, Ossman (2004) discovered how

${ }^{*}$ PhD Student, Indiana University, USA.

${ }^{\dagger}$ Indiana University, USA. 
neighborhood beauty parlors in three different cities, Casablanca, Paris, and Cairo, in the 1990s were places for women to gather together regardless of socioeconomic status "simply to chat" (p. 120). Beyond the services offered by the neighborhood salon, the place was a melting pot of social differences, "a place of face-to-face sociability - real and imagined" as compared to elite parlors that focus on services designed to make one feel special (Ossman, 2004 , p. 121). The informal social space of the coffeehouse or beauty salon provides examples of how the space was utilized for fostering community.

However, the social spaces in which people gather to share an experience have become less social and more private, individual spaces (Giroux, 2003). The decline in social connectedness is supported by the research on the state of American society by Putnam (2000). Putnam indicated that "we engage less often in leisure activities that encourage casual social interaction, we spend more time watching (admittedly, some of it in the presence of others) and less time doing" (Putnam, 2000, p. 115). One potential predictor of the social decline is the expansion of the metropolis from the city to the suburbs.

Oldenburg (1999), in an effort to call for social reform of suburbia, claimed that places, like the coffeehouse or salon, where people voluntarily choose to go outside of the home or work during one's leisure time on a regular basis to engage with others, are a necessity to combat the feelings of loneliness created by living in suburbs as compared with living in the city. The suburbs are seen as being disconnected from the culture and life of people intimately woven together in a city. Arguments against suburbs indicate they are isolating and that suburbanites long for the connection with others (Oldenburg, 1999; Putnam, 2000). Therefore, in the viewpoint of Oldenburg, gathering places would create the space for connection to occur. The creation of these "third places" offers an informal space where no one feels they are hosting but all feel right at home (Oldenburg, 1999, p. 16).

The increase in popularity of mobile media has been linked to the loss of social connectedness as well. Mobile media is said to enable an individual to be alone in the presence of others, also when these are close connections (Pea et al., 2012). At the same time mobile media makes feeling connected possible such as in a coffeehouse when one needs to be alone, for example to read or write (Walsh, White, \& Young, 2009). This paper analyzes how mobile media are used in social spaces by individuals to privatize space, allowing the connection with others while being alone. This phenomenon is referred to as media-based social solitude in this paper.

\section{Media-based Social Solitude}

Social solitude, coined by Leo Coleman (2009), is a concept used to describe the behavior of individuals who seek sociality and solitude simultaneously. As an ethnographic researcher, Coleman spent time in New Delhi at the Volga, a restaurant frequented by homosexual men that "was always populated, but was only occasionally - never for me - a place for encounters that turned into connections" (p. 765). For Coleman (2009), the 
"dominant way of being in that space was being alone together - a pact of mutual privacy only slightly tinctured by mutual surveillance and individual speculation" (p. 765). Coleman defined social solitude as "a socially-shaped, structurally-given kind of solitude in company" (p. 765).

Similar descriptions of social solitude have been made in an attempt to steer society into a new, more positive, direction based on a declining American society (i.e. Putnam's 2000 "Bowling Alone"; Turkle's 2011 "Alone Together"). Putnam (2000) argued that shifts in society such as increasing uses of technology and media and the movement from urban to suburban lifestyles have altered society to be less connected. Since electronic technology can be consumed privately with and without the presence of others, Putnam (2000) found television viewing habits to be the "single most consistent predictor" in being less engaged with others, specifically regarding the decline in civic engagement (p. 231). With the increase in mobile media device use in America, the potential to be alone together is seen to be greater, and potentially more harmful, as it can be brought into public social spaces.

Perhaps we should not question whether or not social solitude is a positive or negative development, but rather explore how it serves as a means to maintain a sense of connectedness in one's leisure time, in the context of mobile media. Therefore, we propose that through the use of mobile media devices, social solitude occurs physically or virtually with others alone together by creating privatized spaces in social places; or media-based social solitude.

\section{The Social Space of Media-based Social Solitude}

The coffeehouses of today provide the physical place for people to gather together, but the space within it may ultimately be used to create privatized niches to be alone. The concept of privatization was once associated with the leisure activities of those with higher social status who would conduct leisure activities more often at home than elsewhere (Allan \& Crow, 1991). Although the concept is still relevant, privatization can extend beyond the walls of a home due to increased mobility and connection to media devices found prevalent in American society. Media devices such as smartphones, tablets, and laptops are popular. The US has more cell phone subscriptions than the total number of the US population (CTIA, 2013). The ability to have alternative work locations, such as coffeehouses, allows individuals to transform a public location into a private one. Oldenburg (1999) commented that coffeehouses, once filled with the primary act of conversing, are now "wax museums for the living dead "Where there is no talk, there is no life" (p. 192). In addition, the media's introduction into public spaces allows people to be entertained anywhere, at anytime, minimizing the feelings of loneliness. Turkle (2011) stated:

In fact, being alone can start to seem like a precondition for being together because it is easier to communicate if you can focus, without interruption, on your screen. In this new regime, a train station (like an airport, a café, 
or a park) is no longer a communal space but a place of social collection: people come together but do not speak to each other (p. 155).

Now public places are a space for people to work, create, and find solitude amongst the crowd. The introduction of mobile media could impact the social cues and norms of the place and space within. From a leisure studies perspective, socialization is seen to be the method in which we learn to navigate the world in or through leisure activities based on the social cues and norms defined by the type of place one is in (Kleiber, Walker, \& Mannell, 2011). Examples of public places without such social norms are trains and airports. Moores (2004) discussed the dynamics between users of mobile communication devices in public trains, specifically an interaction of a woman on a phone in the presence of other passengers. One person kept staring at the woman. When the woman noticed, she responded with defiance. The observed social norms of mobile phone use on the train were a violation of what Goffman (1963) termed "civil inattention" in which one glances at another to acknowledge his/her presence, but politely shows a withdrawal of attention or a shift of gaze (p. 84). When the gaze is sustained, Goffman (1963) stated "it is understandable that staring itself is widely used as a means of negative sanction, socially controlling all kinds of improper public conduct" (p. 88). Therefore, the violation of the social norms of the space may evoke a sense of defensive emotions. Engaging in media in public settings challenges assumptions about what was once considered socially civil behavior.

Some public places create environments that force strangers to come together, such as airports. The use of public space in a terminal can include anything from mobile phone use, watching movies or the TV, and listening to music, to conversing with friends or family and the occasional disgruntled passenger yelling at customer service. All of which are examples of a public space being privatized by individuals or groups who believe privacy social norms exist for public places. Some people may use their personal mobile media in order to lessen the feelings of alienation within a public space. Bull (2004) asserted that "the greater the need for proximity and connection, as expressed through the use of mobile communication technologies, the more alienating the public spaces of daily existence becomes" (p. 278). Those who choose to insert their physical bodies in a public place only to create and manage a media bubble are exercising their freedoms of leisure-time pursuits to happiness. According to Davies (2005), "since the individual is responsible for taking care of him or herself and not dependent on society, such selves, in being cut loose from the social, no longer have the same responsibility to the social" (p. 9). The rules or social norms of shared spaces in a public place are no longer a group process, instead are left to the individual for personal survival.

As mobile media is inserted into the everydayness of one's life, the use in public places is redefining the social space within it. For university students, this may be the coffeehouse located in a student union. College students now seemingly use coffeehouses, once a centrality of conversation among strangers, 
in a more privatized way. It is assumed that the privatization of public space allows individuals to participate in media-based social solitude. For example, mobile media allow college students to bring their home with them wherever they go (Chen \& Katz, 2009). Although varying discourses exist on mediated behavior in a social setting, within and outside of the research realm, not much is known about what this behavior entails.

For the purposes of understanding the phenomenon of media-based social solitude in public places, the following research question guided the research study design:

How do college students engage in media-based social solitude in coffeehouses?

\section{Research Design}

In order to understand media-based social solitude in public places, qualitative inquiry methods were utilized in this exploratory study. According to Denzin and Lincoln (2005), "qualitative research is a situated activity that locates the observer in the world" in which they "turn the world into a series of representations, including field notes, interviews, conversations, photographs, recordings, and memos to the self" (p. 3). One method to understand the lived experience of a phenomenon such as social solitude is to utilize a phenomenological approach. Phenomenology allows for the researcher to interview participants about the lived experience of a shared event (Creswell, 2007), such as studying in a coffeehouse. In the Heideggerian approach to phenomenology, the purpose is "simply the study of appearances" (Mitchell, 2012 , p. 4) thus making the approach acceptable for the appearance of everyday life of a college student. Through the use of observation field notes of both researchers and recorded interviews, the methodological approach provided a triangulation of data for validity (Creswell, 2007).

\section{Field Site Description and Environment}

The location for the study was a large open space connected to a coffeehouse in a student union building at a large public university in a Midwestern town. Since the coffeehouse is well populated throughout the day, it was the ideal location for both observation and interviews. Data collection was conducted over the course of four days in two-hour block sessions. All of the visits to the coffeehouse were conducted during the same time of day, in the morning between 9-11am, to provide consistency in the atmosphere.

Within the coffeehouse, the location criterion for interview selection was distinguished by a pre-selection of specific tables in an eight by seven grid of tables. There are areas to sit outside of this grid by users of the coffee shop. These areas were excluded because of the casual nature of the arrangement 
(sofa, chairs, lounge style seating), and to the degree of difficulty to observe behaviors.

The use of a laptop or mobile phone was the main criterion for inclusion in the recruitment of participants. One of the founding components of the proposed definition of media-based social solitude is the use of a mobile media device to either create a boundary between two individuals physically or as a connection between two individuals virtually, known as "symbolic proximity" (Wei \& Lo, 2006, p. 57). Participants could be sitting alone or with others and could be with or without earbuds or headphones.

\section{Population}

For the purposes of this study, university students were utilized. The Millennial generation, specifically the younger members of the cohort, have been exposed to computers and digital devices since toddlerhood (Lancaster \& Stillman, 2002; Oblinger \& Oblinger, 2005; Prensky, 2011; Twenge 2006). These students are more likely to utilize (multiple) media devices in public spaces than older generations. In the use of phenomenology, traditional sampling methods are not common due to the nature of exploring the meaning of a phenomenon rather than causes of a phenomenon (Schmicking, 2010). In support of non-traditional sampling methods, Creswell (2007) suggested criterion-sampling technique in which all of the cases must meet a set of criteria. Therefore, observations and the subsequent interviews were conducted based on the ability of researchers to be located in proximity to an individual who met the inclusion criteria.

A total of 16 participants met both the criteria for location within the coffeehouse and an interaction with mobile media devices. The space restrictions limited the potential pool of participants. Of the 16 participants, one student left during observation, five students refused to be interviewed, resulting in 15 complete observations and ten full interviews. Of the participants who were interviewed, four were male and six were female. Their average age was 21.2 (range 19 to 29). Even though one of the participants was an outlier (age 29), the comments were relevant to students in the 18-25 year range and were thus included in the sample. All ten interviewees self-identified as Caucasian.

Students were asked to self report their major and cumulative grade point averages (CGPA). The average CGPA was $3.51(\mathrm{SD}=0.27)$ and the most common theme to majors was associated with healthcare (i.e. pre-med, speech pathology, dietetics). Further, three of the ten students interviewed were speech pathology or speech and hearing majors.

\section{Data Collection Procedures}

This study was conducted in two stages; observations were followed by interviews. Before beginning the observations and interviews, research signs were placed in clearly visible locations within the field site to inform 
individuals in the space of the observations to be conducted. By placing signs stating "Observations in Progress" with the contact information for the researchers, we felt that the obligations to uphold ethical practices were met. Approval by the Institutional Review Board was granted for all stages of this study (\#1403147974).

Observation. The first stage was the observation of an individual who was sitting in the center of the coffeehouse location. Two researchers were conducting observations simultaneously. The first researcher utilized a quantitative approach to observing the shift in gaze away from a primary task as identified at the beginning of a ten-minute observation time-frame. The results of this component will not be discussed in depth for this qualitative paper. The second researcher sat in a location behind the participant and at an angle. The angle allowed the researcher to observe all tasks being conducted during the same ten-minute time-frame of observation. For the entire ten minutes, the second researcher typed up all the activities of the participant. Immediately upon completion of the first stage, the second stage of the research began.

Interview. In the second stage, the second researcher first asked if the observed would be willing to participate in a research study on media use in a public place in a brief interview and provided a study information sheet. If the participant said yes, then he or she was interviewed. The interview was recorded and transcribed. An initial question "What was your experience sitting in this space using multiple media devices in the last ten minutes?" was asked to each participant. Once a satisfactory answer was obtained, follow up questions were asked. Socio-demographic questions were gathered on age and ethnicity, in addition to school related questions on year, major, and cumulative grade point average. If any observed participant said no to the interview, they were not included and a notation was made on the observation sheet.

\section{Data Analysis}

The primary purpose of the data analysis for this study is to identify repetitive themes based on the interview participants' answers and behaviors. All recordings were transposed into a document, and then coded for themes using QDA Miner Lite software. Participants' direct quotations in the findings section then support the interpretations of the themes. Being transparent in qualitative studies by using verbatim responses helps support the quality and rigor of the study.

\section{Findings}

Investigating the emerging themes based on the research question of "how do college students engage in media-based social solitude" resulted in two main areas: focus and acceptance of media. This section will discuss each relevant theme, supported by interview statements. 


\section{Presence of Others Enables Focus}

Observation of Millennial students in a coffeehouse over the course of several days provided insight into what media-based social solitude looks like. Upon arrival to the coffeehouse each day, the level of activity in the space was minimal, but increased as time progressed. Level of activity includes the number of tables occupied by students, the noise level, the interaction between individuals, and activity at the café counter nearby.

With the increase of intensity of activity, one would have hypothesized that college students do not focus on the task at hand. However, of the fifteen observations, five students were so focused on studying that they did not want to be interrupted to participate in the interview. Indeed, each person who refused the interview portion of this study had been deeply focused on studying for an exam or paper that was due that day in the previous ten-minute observations of behavior. While observing a female who refused to be interviewed because of a test, a female entered the social space while loudly talking. The observed participant spent several seconds gazing toward the distracting individual and seemed disturbed by the distraction. Although these students were in a public place, they did not want to be disturbed; resulting in a defensive staring. In essence they privatized the public space and excluded others while at the same time needing them to be productive.

When asked for the reason to come to the coffeehouse on that particular day, several participants among those interviewed reflected on the need for background noise to help them focus on or accomplish the task at hand. These responses were similar among people who were sitting alone and had or did not have earbuds or headphones on. Responses were:

I guess I like it here because there is a lot of background noise, but not a specific sound that I can isolate ... it's more like good white noise. Just in case, I listen to my headphones. (Male, sitting alone with headphones)

Because there are a lot of people studying, but there is also background noise and it's not dead silent, so if I'm talking to someone else it's easy to study with. (Female, sitting alone with earbuds in)

I realize for some people that being in a crowded place doesn't help, but as long as it's not too loud or disruptive, I kind of like having the motion around me ... like being able to focus on what I am doing, but in an odd way, it's kind of exciting to have other things going on around you. (Male, sitting alone with earbuds in)

It's a little bit noisy, but I kind of find that noise distracts or kind of keeps me focused on studying, I like to have things going on around me or if it is too quiet, I try to find other things to do, so I do like the atmosphere in here ... it's not as quiet as the library - I like the interaction. (Female, sitting with another female without earbuds) 
This sense of surrounding noises created by others in the environment seems to be a reason for engaging in media-based social solitude. When asked about concentration levels, respondents indicated this reinforcement of others providing comfort or focus for the task at hand:

I like to have background noise, but not like distracting background noise, so like random a conversation that I don't know what's going on. They're easy to tune out, but it's not so easy that I feel trapped in silence. (Female, sitting alone without earbuds)

... if I'm just doing casual tasks that doesn't take my entire attention, I like to come to a coffee shop and it kind of breaks things up because I get a little bit ADHD when I study. I kind of try to jump around between two different things, so this kind of keeps me in one place. When I have other people around me, it kind of keeps me grounded in one spot and focusing. (Female, sitting with another female without earbuds)

The similarities in the participants' rationale for needing background noise to support the need to focus, begs the question that the role mobile media devices play in providing the background noise. Students who chose to go to the coffeehouse to study because they needed the reinforcement of others were also those who wore earbuds or headphones in the space, which ultimately guarantees a sense of privatization of the public space. This leads to the second theme of the acceptance of media.

\section{Acceptance of Media in a Social Space}

The second emergent theme, acceptance of using media in a social space by the user as well as surrounding others - surfaced through the observation of social practices within the social space as well as the interviews with observed participants. The general acceptance of the use of media while in a social space can be best described as a tension between negative and positive viewpoints of phone, tablet, laptop or headphone use. Moreover, the type of media used as well as the task at hand seem to be connected to the extent to which the social space is privatized, and what is considered acceptable. The students that were in the coffeehouse to study were less acceptant of the traditional use of the social space (e.g. loud chatter) and were more likely to confine their social space to the table they were sitting at. Their interactions with the social environment were limited, and gazes that went beyond that limited space seemed to be directed inward, for the purpose of thinking and memorizing. Media devices in these instances were mainly used for study purposes. People with a study task that was less emergent or who were less focused for other reasons, were more prone to look up and around and take in the social environment and interrupt tasks to chat with a friend if present. Then mobile media were used to aid in studying but also to engage in seemingly unrelated tasks such as going on Facebook, shopping websites, and showing pictures on 
the phone to a friend. The excerpts below show examples of the connections between the tasks at hand, privatization of the space, and type of media use.

Based on the information gathered through the observations in ten-minute segments, the use of earbuds was most frequent among people who were alone compared to with someone. Of the fifteen observations, eight individuals were using earbuds or headphones, and only one of those eight was observed using headphones while sitting with someone else at the table. Unfortunately, this person denied a request for an interview due to an upcoming exam he was studying for.

Those who allowed interviews felt mobile media devices were a distraction yet still felt the need to use them, and for those who felt the use was a necessity to complete the task at hand. For one respondent, when asked how she felt about using media devices while sitting with someone, indicated that it was difficult to talk with each other even without having earbuds in because of the media devices. She stated,

I think it is harder for both of us to talk to each other, because if she's on hers and I'm on mine, then we are both trying to do multiple things at once, so it becomes harder to talk even to each other.

There seems to be a level of being alone, together without the use of earbuds as a physical barrier to interaction. Media use then is considered a distraction, yet still seen as a necessity.

Upon observing the interactions of one male sitting with another male without earbuds in, there seemed to be little interaction as each worked on their separate media devices. During the interview with this young male, he stated, "We just happened to sit together" even though they know each other "pretty well". Therefore, even just the act of sitting together with a close friend does not determine if there will be social interaction. In general, the reason for being in the coffeehouse seemed to determine the level of social interaction for an individual. For most, this specific social space seemed either a place to study or to kill time in between classes. The main purpose of visiting this social place, then, seemed not to socialize, but rather to not feel alone.

The previous narratives are examples of the tensions between the interactions of mobile media for the individual as well as the surrounding others. However, the observations and interviews also shined a light on how mobile technology is used to negotiate leisure time in a social space. An exceptional case of positive motivation to work through mobile devices was noted by one particular respondent's use of an application on her mobile phone. The application monitored her phone use and donated to a charity for a day's worth of clean water for every ten minutes of non-phone use. She stated, "I've been doing that a lot lately when I study," and it encourages her to continue to study by being a part of a collective group, through the app, to assist people in need. Knowing that she was supporting healthy drinking water for individuals in Africa by studying without using her phone was a powerful incentive for focused study time. 
This previous example shows how a social space as a coffeehouse has changed in its social dynamics. The physical social space has narrowed while, at the virtual level social space, the social interactions that take place through the mobile devices have widened. The surrounding others enhance the comfort levels of being alone while the mobile devices provide the option of bringing others close into the social space. Moreover, the type of media technology that is present signals to the environment the level of social interaction one desires. Earbuds, for example, were generally a sign of the need for social solitude, both virtually as well as physically.

\section{Discussion}

The findings of this exploratory study enable discourse about the characteristics of the phenomenon of media-based social solitude that is introduced in this paper. The themes focus and acceptance of media in a social space that emerged from the observations and interviews provide nuances to the concept of social solitude and challenge the traditional (largely negative) viewpoints of the contemporary use of social spaces. Mainly, the current paper exemplifies how mobile media alter the dynamics of a social space.

The definition of social solitude being a "pact of mutual privacy only slightly tinctured by mutual surveillance and individual speculation" (Coleman, 2009, p. 765) seems to be supported by the participants' statements. The use of media provides a clearer picture into the phenomenon of social solitude within a mobile media context. Participants' consistent expressions of needing background noise created by other people as reinforcement to be focused are a direct example of solidarity in solitude. If everyone in the coffeehouse is studying, and the known social norms of the space include being allowed to talk (as compared with a library that commands silence), then the space itself, along with the use of media, create the sense of collectivity, of solidarity in the woes of studying. These findings similarly support the outcomes of Ito (2005) that mobile media does not "inherently" disrupt an existing social space and the associate norms of the place.

Further, based on the two themes that emerged about how college students engage in media-based social solitude in a coffeehouse, the definition of social solitude (Coleman, 2009) can be analyzed in greater detail. The creation of privatized space by selecting the perimeter tables first before filling the center of the room supports a portion of the definition of the "socially-shaped, structurally-given kind of solitude in company" (Coleman, 2009, p. 765). The social structures of the space could support the need for solidarity in solitude. The social structures also include the social norms of the space. While observing a participant, one such example included a young woman who entered the space loudly and overtly drew attention to herself and the people she knew. This young woman's behavior caused the person being observed to look over in the young woman's general direction, and seemed displeased with the distracting behavior. The observed behavior supported Goffman's 
description of negative sanctions such as staring at an individual with hopes to induce proper social behavior such as not attracting attention to ones' self.

Conducting observations in a coffeehouse led to a contradictory finding to Oldenburg's (1999) statement that coffeehouses provide spaces where people do not talk or that there is "no life" (p. 192). During the observations, the level of activity over time rose to a noise level that caused difficulty at times to hear the recordings of people being interviewed. In addition, even though the campus is large, students know each other through organized social groups such as sororities or fraternities. When they walk into the shared space, their friends will call out to them or bring attention to their arrival adding to the lively atmosphere. So in contradiction to Oldenburg (1999), coffeehouses on college campuses are alive and vibrant with conversation.

The need for background noise to aid in the appropriate level of focus supports the findings of Mehta, Zhu, and Cheema (2012) that demonstrated that a moderate level of background noise reinforced the creativity among college-aged populations. When the level of noise becomes too loud, the level of distraction increases, which decreases cognitive processing. As mentioned by several participants, when the noise level becomes too much, the use of headphones or earbuds reduces the background noise to an acceptable level to focus again.

The theme of acceptance of mobile media device use in public, social spaces supports the findings from other qualitative and quantitative studies. Observations of the (study) behavior of 700 participants in four areas of a library, Paretta and Catalano (2013) found that the use of social media in a space designed for study was the second most common behavior after reading print materials. The use of social media to widen the social space landscape allows participants to feel connected. Even though the use of technological devices is seen to be a distraction and a tool for study, college-aged students are seeking spaces on campuses to privatize it while also making it into a social space. The acceptance of media use to privatize space through the use of headphones or earbuds is supported by the findings of Garner's (2014) study of iPod use and introversion. iPod users are perceived to be isolated from the social environment and to engage less in the social experience by non-iPod users. However, the users of the devices do not necessarily use it to deflect social interaction, but for the purposes of enjoyment. The current study adds to this by arguing that technologies such as earbuds are used to keep the comfort of the social space on sufficient distance to create a safe space for focus. Thus, the use of mobile media devices, which include iPod type technologies, may be perceived as isolating by some, yet from the users' perspective they are helpful in achieving a specific task because it allows them to feel connected, physically or virtually, during a task that requires one to be alone. In the case of this study, it seemed to be understood and accepted, although perhaps unconsciously, amongst the visitors of the social space that technology use is part of a social space. 


\section{Future Directions}

The current study observed media use in a public space within a university that is mainly used by university students. It is likely that the setting and the visitors of the coffeehouse make for social dynamics that are distinct from other coffeehouses. The main aim of most students was to pass time between classes or to study. As the purpose of the visit influences the way social solitude is expressed, more observations are needed in different public spaces to be able to find a pattern in media-based social solitude behaviors. Alternative techniques to understand the phenomenon would include the use of photo-solicitation, video recordings, and in-depth interviews with more individuals. The length of time for the study observation time and duration of observations per participant can be extended to provide further inside in mediabased social solitude.

The ubiquitous nature of media use in social spaces leads to further questions about how individuals perceive their own media-based social solitude behavior. However, for the purpose of the current study, the relevance of media-based social solitude is rooted in the understanding of college student leisure time activities. Although the place, the coffeehouse, is an informal thirdspace in which it is not home or work, it is a leisure location. College students chose to sit in a leisure location and attempt to focus on school-related activities. This study shows how difficult that task is, yet socially acceptable, in a mediated world in which connectivity occurs at anytime, anyplace, anywhere.

\section{References}

Allan, G., \& Crow, G. (1991). Privatization, home-centredness and leisure. Leisure Studies, 10(1), pp. 19-32.

Bull, M. (2004). To each their own bubble: Mobile spaces of sound in the city. In: Couldry, N. \& McCarthy, A. (Eds.) Mediaspace: Place, scale and culture in a media age. (pp. 275-293). New York, NY: Routledge.

Chen, Y. F., \& Katz, J. E. (2009). Extending family to school life: College students' use of the mobile phone. International Journal of Human-Computer Studies, 67(2), pp. 179-191.

Coleman, L. (2009). Being alone together: From solidarity to solitude in urban anthropology. Anthropological Quarterly, 82(3), 755-777.

Creswell, J. W. (2007). Qualitative inquiry and research design: Choosing among five approaches, $\left(2^{\text {nd }}\right.$ ed.). Thousand Oaks, CA: SAGE Publications.

CTIA - The Wireless Association. (2013, January). Wireless quick facts. Retrieved from http://goo.gl/ZZT15a.

Davies, B. (2005). The (im)possibility of intellectual work in neoliberal regimes. Discourse: Studies in the Cultural Politics of Education, 26(1), pp. 1-14.

Denzin, N. M., \& Lincoln, Y. S. (2005). Introduction: The discipline and practice of qualitative research. In: Denzin, N. K. \& Lincoln, Y. S. (Eds.), The Sage Handbook of Qualitative Research ( $3^{\text {rd }}$ ed., pp. 1-32). Thousand Oaks, CA: SAGE Publications. 
Garner, B. R. (2014). iPod use and the perception of social introversion. Leisure Studies, 33(1), pp. 22-31.

Giroux, H. A. (2003). Public spaces, private lives: Democracy beyond 9/11. Linham, MD: Rowman \& Littlefield.

Goffman, E. (1963). Behavior in public places. New York, NY: The Free Press.

Ito, M. (2005). Mobile phones, Japanese youth, and the re-placement of social contact. In: Ling, R. \& Pederson, P. E. (Eds.) Mobile Communications, (pp. 131-148). London: Springer.

Kleiber, D. A., Walker, G. J., \& Mannell, R. C. (2011). A social psychology of leisure. State College, PA: Venture Publishing, Inc.

Lancaster, L. C., \& Stillman, D. (2002). When generations collide. Who they are, why they clash. How to solve the generational puzzle at work. New York: Collins Business.

Mehta, R., Zhu, R., \& Cheema, A. (2012). Is noise always bad? Exploring the effects of ambient noise on creative cognition. Journal of Consumer Research, 39(4), pp. 784-799.

Mitchell, D. (2012). Everyday Phenomenology. Newcastle upon Tyne, UK: Cambridge Scholars Publishing.

Moores, S. (2004). The doubling of place: Electronic media, time-space arrangements and social relationships. In: Couldry, N. \& McCarthy, A. (Eds.) Mediaspace: Place, scale and culture in a media age (pp. 21-36). New York, NY: Routledge.

Oblinger, D., \& Oblinger, J., (Eds.) (2005). Educating the Net Gen. Washington, D.C.: EDUCAUSE

Oldenburg, R. (1999). The great good place: Cafes, coffee shops, community centers, beauty parlors, general stores, bars, hangouts and how they get you through the day. New York, NY: Marlowe and Company.

Ossman, S. (2004). Media, bodies and spaces of ethnography. In: Couldry, N. \& McCarthy, A. (Eds.) Mediaspace: Place, scale and culture in a media age. (pp. 114-125). New York, NY: Routledge.

Paretta, L. T., \& Catalano, A. (2013). What students really do in the library: An observational study. The Reference Librarian, 54(2), pp. 157-167.

Pea, R., Nass, C., Meheula, L., Rance, M., Kumar, A., Bamford, H., Nass, M., Simha, A., Stillerman, B., Yang, S., \& Zhou, M. (2012). Media use, face-to-face communication, media multitasking, and social well-being among 8-to 12-yearold girls. Developmental Psychology, 48(2), p. 327.

Prensky, M. (2011). Digital wisdom and homo sapiens digital. In: Thomas, M. (Eds.) Deconstructing digital natives (pp.15-29). New York, NY: Routledge.

Putnam, R. D. (2000). Bowling alone: The collapse and revival of American community. New York, NY: Simon \& Schuster Paperbacks.

Schmicking, D. (2010). A toolbox of phenomenological methods. In: Gallagher, S. \& Schmicking, D. (Eds.) Handbook of Phenomenology and Cognitive Science. Dordrecht, Netherlands: Springer.

Turkle, S. (2011). Alone Together. New York, NY: Basic Books.

Twenge, J. M. (2006). Generation me: Why today's young Americans are more confident, assertive, entitled - and more miserable than ever before. New York, NY: Free Press.

Walsh, S. P., White, K. M., \& Young, R. M. (2009). The phone connection: A qualitative exploration of how belongingness and social identification relate to mobile phone use amongst Australian youth. Journal of Community \& Applied Social Psychology, 19(3), pp. 225-240.

Wei, R. \& Lo, V. (2006). Staying connected while on the move: Cell phone use and social connectedness. New Media and Society, 8, pp. 53-72. 